\title{
Formas de adhesión al Islam en Argentina: conversión, tradición, elección, reasunción y tránsito intra-islámico.
}

\author{
Forms of adhesion to Islam in Argentina: \\ conversion, tradition, choice, return to religion and intra-Islamic transit
}

\author{
Silvia Maria Montenegro*
}

\begin{abstract}
Resumen
En Argentina, como en otros países de América Latina, el Islam llega como religión de inmigrantes, principalmente sirios y libaneses, entre finales del siglo XIX y las primeras décadas del Siglo XX. En la historia de su presencia local es posible reconocer tres etapas que implican distintos momentos de institucionalización, diversificación, visibilidad y negociación de reconocimiento en el espacio nacional. Actualmente la religión musulmana se configura como una opción en un campo religioso plural y cada vez más, aunque en grado diverso, las comunidades cuentan en su membresía tanto con musulmanes de origen como con convertidos. Este artículo enfoca la adhesión al Islam como un proceso dinámico, que incluye pertenencias por conversión, tradición, elección, retorno e itinerancias intra-islámicas entre nacidos musulmanes. Desde un abordaje etnográfico tendremos en cuenta trayectorias individuales de conversos y musulmanes de origen, estableciendo un diálogo crítico con la literatura específica sobre conversión al Islam. Este trabajo también problematiza la dicotomía convertidos/nacidos musulmanes, en pos de lograr una comprensión más amplia de las dinámicas de la adhesión al Islam.
\end{abstract}

Palabras clave: Islam; Musulmanes; Argentina; conversión; tradición.

\begin{abstract}
As in other Latin American countries, Muslim presence in Argentina traces its origin to Arab migration waves in the late nineteenth and early twentieth century; most of these immigrants came from Lebanon and Syria. We can identify three historical periods; each of these stages involves different degrees of institutionalization, diversification, visibility and negotiation of recognition in the national arena. Currently, Islam is one of the religious options available in a plural religious field and, increasingly, the communities are composed of Muslim Arab descendants and converts. This paper analyze the adhesion to Islam as a dynamic process that includes conversion, tradition, return to religion and intra-Islamic transit among Muslim descendants. Using an ethnographic approach I will examine individual trajectories of converts and Muslim descendants, on the basis of these analyses I will try to establish a critical dialogue with the literature on conversion to Islam. This article also problematizes the converts/Muslim descendants' dichotomy in order to arrive at a more comprehensive understanding of the dynamic of adhesion to Islam.
\end{abstract}

Keywords: Islam; Muslims; Argentina; conversion; tradition.

Artigo recebido em 23 de abril de 2015 e aprovado em 29 de junho de 2015.

${ }^{*}$ Doutora em Sociologia. Professora do Departamento de Antropologia sócio-cultural da Universidad Nacional de Rosario, Argentina. País de origem: Argentina. E-mail: silmarmont@gmail.com. 


\section{Introducción}

La presencia institucional del Islam en la Argentina puede dividirse en tres etapas. La primera corresponde al Islam como una religión de inmigrantes y abarca las cuatro primeras décadas del siglo XX, cuando árabes musulmanes, minoritarios en el contexto de una inmigración cristiana, fundan los centros religiosos más antiguos, algunos de los cuales se mantienen activos hasta el presente, mientras otros no superaron la etapa fundacional. La segunda se produce a partir de la década de 1980 y está marcada por una diversificación institucional, se fundan nuevas mezquitas y asociaciones y las vertientes shiitas del Islam se afirman en el campo religioso nacional con el respaldo de la República Islámica de Irán. Entre finales de los años 80 y comienzo de la década del 90, se suman algunas vertientes del sufismo, como la orden Naqshabandi, que cuenta al menos con 10 sedes a lo largo del país ${ }^{1}$, más otras escisiones de su rama original. Otras expresiones del sufismo circunscriben su acción a la ciudad de Buenos Aires, como el caso de las orden Yerrahi Al Halveti y un desprendimiento posterior de la misma, la tariqa Halveti Jerrahi (KERMAN, 2007). Podemos considerar que la tercera etapa se inicia aproximadamente en el 2000 e incluye la inauguración del centro islámico más grande de América Latina, el Centro Cultural Islámico Custodio de las dos Sagradas Mezquitas Rey Fadh, creado a instancias de la Embajada de Arabia Saudita. En este período también asistimos a una nueva visibilidad del Islam en el espacio público, a partir de la participación de algunas instituciones en actividades interreligiosas, la creación de entidades que nuclean otras ya existentes, el acceso a espacios en medios de comunicación y la consolidación del Centro Islámico de la República Argentina (CIRA) como institución privilegiada de interlocución con el estado. Recientemente también fue creada la Federación de Entidades Islámicas de la República Argentina (FEIRA)

\footnotetext{
${ }^{1}$ El Bolsón (Río Negro), La Consulta (Mendoza), San Lorenzo (Santa Fe), Mar del Plata (Prov. Buenos Aires), Rosario (Santa Fe), Chascomús (Prov. Buenos Aires), Capilla del Monte (Córdoba) Glew (Prov. Buenos Aires), La Plata (Prov. Buenos Aires) y Ciudad Autónoma de Buenos Aires.
} 
que reúne entidades shiitas y alauitas². Otros inmigrantes, como los senegaleses, también contribuyen con sus cofradías a diversificar el panorama de la presencia musulmana3.

A lo largo de esas décadas el Islam se fue tornando una opción religiosa más allá de los círculos que originalmente lo restringían a los inmigrantes árabes y sus descendientes, y fue incorporando conversos argentinos. Aunque no existen datos estadísticos sobre el número de musulmanes en Argentina, a excepción de los ofrecidos por las propias instituciones religiosas, que estiman entre $450.000 \mathrm{y}$ 700.000 fieles, sabemos que los conversos comparten muchos espacios institucionales con musulmanes de origen y que los motivos y caminos de la conversión son diversos 4 .

Este artículo analiza las formas de adhesión al Islam como un proceso dinámico que incluye tanto conversiones de quienes ingresan por primera vez a la religión como permanencias por tradición o “elección”, tránsitos e itinerancias intra-islámicas entre nacidos musulmanes. Desde un abordaje etnográfico tendremos en cuenta trayectorias individuales de conversos y musulmanes de origen, estableciendo un diálogo crítico con la literatura específica sobre conversión al Islam y con trabajos que anteriormente realizamos para el caso de Brasil.

La mayoría de las comunidades musulmanas de América Latina están compuestas por musulmanes de origen y por conversos y la proporción de ambos grupos varía, entre otros factores, de acuerdo a la presencia numérica de

\footnotetext{
${ }^{2}$ La FEIRA fue creada en agosto de 2013 con el objetivo de nuclear y estimular el desarrollo de instituciones ya existentes, que pertenecen a la vertiente shiita y alauita del Islam: Asociación Árabe Argentina islámica, Asociación Civil y Cultural APAIB, Asociación Islámica Alauita de Beneficencia, Asociación Islámica Alauita de Beneficencia de La Angelita, Asociación Islámica de Beneficencia Hagg Yusif, Asociación Islámica de Beneficencia La Unión Alauita, Asociación Argentino,Islámica de Cañuelas, Casa para la Difusión del Islam, Centro Cultural Islámico de Trelew, Centro de Altos Estudios Islámicos de Neuquén, Centro Islámico de Jujuy, Centro Islámico de Mar del Plata, Fundación Islámica de Ayuda Social Organización Islámica Argentina - Mezquita at-tauhid, Organización Islámica Argentina de Tucumán y Unión de Mujeres Musulmanas Argentinas - UMMA.

${ }^{3}$ Para un análisis de la institucionalidad del Islam en Argentina ver MONTENEGRO, 2014.

${ }^{4}$ Según la Oficina Islámica para América Latina el número de musulmanes asciende a 700.000, el Centro de Altos Estudios Islámicos se refiere a 450.000 y el Centro Islámico de la República Argentina estima entre 500.000 y 700.000 musulmanes en todo el país. En cuanto a los conversos es aún más difícil estimar una cifra, al tratarse de un proceso dinámico con entradas y salidas y que se remonta a las últimas décadas.
} 
descendientes de musulmanes de origen, niveles de apertura institucional para con los convertidos, despliegue de estrategias para su inclusión y contacto de los líderes religiosos con los nuevos miembros para la transmisión de conocimiento. En general, los estudios han enfatizado la distinción entre musulmanes de origen y conversos, dado que ambos grupos parecen construir modos específicos de identificación con el Islam5 , prestando menos atención a los modos de adhesión de los nacidos en la religión, generalmente de ascendencia árabe, considerados per se musulmanes. Intentaremos demostrar que el universo de los nacidos en la religión lejos de ser estático muestra desafiliaciones, tránsitos internos entre doctrinas y prácticas de la religión y reasunciones, constituyendo modos de adhesión religiosa específicos de ese universo pero también comparables al de los conversos. Aunque las narrativas individuales de los convertidos y de los musulmanes de origen deben ser puestas en el contexto de las distintas comunidades e instituciones musulmanas a las que pertenecen, pues se relacionan con la historia, proyectos identitarios y orientación de las mismas, elegir casos individuales nos permite abarcar un abanico más amplio de modos de adhesión. En tal sentido, nos interesa prestar atención a la reflexividad de los fieles sobre sus propias biografías religiosas ${ }^{6}$. Comenzaremos analizando los criterios de construcción de tipologías de conversión al Islam en algunos trabajos sobre el tema en distintos contextos empíricos, poniendo esa literatura en diálogo con los patrones construidos a nivel local a partir de nuestra experiencia etnográfica. Posteriormente, haremos referencia a los lenguajes que asume la conversión en Argentina, considerando regularidades construidas a partir de la narrativa de

\footnotetext{
${ }^{5}$ Para el caso de Brasil, Paulo Pinto afirma que el proceso de incorporación de los nuevos convertidos al Islam no se produjo en el sentido de diluirlos en el conjunto de fieles de las comunidades musulmanas de Brasil, sino en el de posicionarlos en un constante debate con los musulmanes cuyo origen está ligado a la inmigración árabe (PINTO, 2010, p. 213). Para ejemplos de ese debate entre musulmanes de origen y convertidos, ver también FERREIRA, 2013.

${ }^{6}$ Entiendo por biografías religiosas a las trayectorias de adhesión, desafiliación, preferencias y búsquedas religiosas referidas por los actores como parte de su historia personal pasada. Se trata de una reconstrucción narrativa a través de la cual los sujetos explican cómo llegaron a formar parte de una religión determinada y cómo rememoran su vida religiosa anterior a dicha filiación. Tal proceso reflexivo se plasma en los discursos que tomamos como materia prima para nuestro análisis.
} 
conversos; por último, abordaremos los modos de adhesión de nacidos musulmanes a partir de ejemplos representativos7.

\section{Patrones y tipologías sobre la conversión al Islam}

La literatura existente sobre conversión al Islam podría clasificarse en dos ejes: los estudios históricos que analizan, por ejemplo, procesos como la islamización de África o durante el Imperio Otomano y los estudios sobre la conversión al Islam en las sociedades contemporáneas, dentro de los cuales existen algunos subtemas, como la conversión de mujeres al Islam ${ }^{8}$ y la conversión a partir del sufismo9. Estos abordajes se inscriben en el campo más amplio de los estudios sobre la presencia musulmana en sociedades donde el Islam es una religión minoritaria y, en general, fueron incrementándose en los últimos veinte años. A pesar de las grandes diferencias contextuales, y excluyendo aquí la especificidad de conversión femenina y al sufismo, es posible agrupar los trabajos que se refieren puntualmente a la conversión en Estados Unidos, algunos países europeos y, de modo más incipiente, en América Latina, dado que se trata de espacios donde los nuevos musulmanes provienen de ambientes religiosos que, en un sentido general, podemos considerar "cristianos".

No existen comparaciones globales de los patrones de conversión pero sí, como veremos, algunas establecidas a partir de dos o más países o contextos.

\footnotetext{
${ }^{7}$ Para el análisis de la conversión construimos patrones a partir de 28 entrevistas a individuos que frecuentan o frecuentaron instituciones en distintas ciudades de Argentina ( 26 hombres y 2 mujeres), con una antigüedad de conversión entre 15 y 3 años. Para el caso de los modos de adhesión de nacidos en la religión nos basamos en conversaciones en contextos de observación participante y también fuera de espacios institucionales, con musulmanes de origen árabe, hombres en su totalidad. En todos los casos usamos nombres ficticios y evitamos la referencia a instituciones para preservar el anonimato de quienes aceptaron narrar sus experiencias. El trabajo de campo fue realizado entre 2009 y 2013 como parte de otros proyectos más amplios sobre la presencia musulmana en Argentina y otros espacios latinoamericanos. Dado el desbalance de género de la muestra es probable que nuestras conclusiones no puedan generalizarse al universo femenino de adeptos al Islam. Esta investigación se ajusta a las normativas vigentes del comité de ética del Consejo Nacional de Investigaciones Científicas y Técnicas (CONICET).

${ }^{8}$ Para una visión general sobre la conversión femenina a partir del estudio de casos por países pueden consultarse las siguientes colecciones: MANSSON MCGINTY, 2006 y VAN NIEUWKERK, 2006.

${ }^{9}$ La globalización del sufismo, su presencia en sociedades occidentales y las formas de adhesión de convertidos ha sido objeto de investigaciones específicas, constituyendo un interesante capítulo de la literatura sobre el tema. KOSE, 1999, incluye un capítulo sobre el ingreso al Islam a través del sufismo en su libro sobre conversos en Gran Bretaña. Entre la muy amplia bibliografía y para un panorama sobre una variedad de grupos en distintos países, ver DRESSLER \& KLINKHAMMER (2009) y WESTERLUND (2004), entre varios otros.
} 
Tanto las similitudes como las diferencias remiten a que en estos diferentes espacios el Islam se remonta, inicialmente, a determinados procesos migratorios, logró determinado tipo de visibilidad y posición en los campos religiosos locales, se inserta de modo peculiar en la modalidad de las relaciones entre estados y minorías religiosas. Al mismo tiempo, las comunidades tienen distintos grados de aceptación social, atravesaron o atraviesan procesos de estigmatización, fortalecimiento o transformación institucional, entre otros factores determinantes. De ahí que la aproximación de conversos en comunidades e instituciones nuevas o ya existentes esté marcada por la especificidad contextual. Numerosos trabajos optan por centrarse en las narrativas de los sujetos, con poca alusión a los ambientes institucionales en los que se da y mantiene la conversión. Nos detendremos en algunos patrones y tipologías para considerar su valor heurístico a la hora de iluminar en un sentido más amplio la adhesión al Islam entre musulmanes de Argentina que, desde nuestro punto de vista, incluye tanto las conversiones como los sentidos de pertenencia de los nacidos en la religión.

La mayoría de los estudios sobre el tema toma un conjunto de casos individuales para conocer los significados otorgados por los individuos a su proceso de conversión. En tal sentido, siguen las líneas generales de los estudios de conversión contemporáneos, cuyos énfasis son bien sintetizados por Rambo (2014, p. 7-8): enfoque de continuidades y discontinuidades entre la orientación religiosa pasada y actual; consideración del converso como un agente activo que, por ejemplo, negocia su nueva opción religiosa con su entorno; reconocimiento de la complejidad y diversidad de motivaciones; importancia de las narrativas; relevancia del cuerpo como espacio de acciones, comportamientos y rituales que hacen a la adhesión y atracción religiosa y atención a las conversion careers más que a la conversión como un hecho súbito, radical y permanente.

A seguir indagaremos si en algunos de estos estudios es posible encontrar elementos que puedan considerarse específicos de la conversión al Islam y cuáles 
son los criterios para la construcción de tipologías. Tendremos en cuenta que estos abordajes combinan o superponen tres dimensiones: un diagnóstico del contexto religioso previo de los sujetos, la detección de factores de atracción vistos como intrínsecos al Islam y una clasificación de los caminos que conducen a la efectivización de la conversión. El trabajo de Kose $(1996$; 1999) está entre los que enfocan las narrativas de los conversos para considerar las motivaciones esgrimidas en términos de continuidades y discontinuidades de la religión anterior y comprender aquello que los lleva a permanecer en su nueva identidad. Analizando más de 70 entrevistas a conversos en Gran Bretaña se detiene en los motivos de la desafiliación previa de los sujetos, bajo la idea de que ésta se relacionaría con la dinámica del cristianismo en Inglaterra, al cual los conversos cuestionan más en términos de prácticas (permisividad, moralidad, hipocresía) que de creencias. Así, los convertidos aparecen como sujetos que buscan significado y estabilidad en el Islam, identificándolo como modo de vida y como una fe más tradicional, ante un medio "post-cristiano" y secular que otorga un papel marginalizado a la religión. El denominador común aquí estaría dado por el contexto (secular y post-cristiano) en que los sujetos buscan una adhesión religiosa más fuerte y por aspectos que hacen a lo que el autor llama “post-conversión”, como una etapa de manutención de la nueva identidad islámica. Kose afirma que los conversos ingresan en una especie de "transición cultural", preguntándose si occidentalizarán el Islam o se asimilarán a la cultura musulmana en un sentido amplio (KOSE, 1996: p. 137). Más allá de lo inconducente que puede resultar formular esta pregunta en términos dicotómicos, la idea de la existencia de una "transición cultural" remite a la especificidad del mundo de los conversos que, como sabemos, se construyen y son construidos como diferentes en la convivencia con musulmanes de origen. Casi dos décadas después, Ahmed propone un enfoque similar, esta vez en Estados Unidos, y enfatiza que los motivos enunciados por los convertidos demuestran su estado de insatisfacción en relación a valores de la "sociedad occidental”. Aunque los motivos parecen variar según los subgrupos de convertidos analizados (mujeres blancas, hombres blancos, latinos, cubanos en 
Miami), todos parecen rechazar ciertos aspectos de la cultura norteamericana: crisis, "excesos", o demasiada libertad ante la cual la cristiandad habría tenido un papel de tolerancia (AHMED, 2010, p. 351). En ese contexto el Islam sería atractivo porque representaría una tradición que aun preserva los valores del honor y la vergüenza y ofrece roles que, por ejemplo, en el caso de las mujeres, operarían como antídoto a aquellos ante los cuales se sienten insatisfechas. Sin establecer un patrón riguroso y reconociendo la diversidad de lo que en cada subgrupo parece motivar la conversión, Ahmed se refiere al Islam como una alternativa espiritual a la cual los sujetos se aproximan motivados por: la búsqueda a través del estudio y la razón de verdades universales, la curiosidad (incrementada después del 11S), la búsqueda de orden y disciplina en la vida, la atracción ejercida por la noción islámica de ummah que rechaza barreras raciales y nacionales o, simplemente, por razones económicas o por motivos matrimoniales (AHMED, 2010, p. 305). Para ambos autores los motivos de la conversión pueden ser diversos, pero el Islam parece atractivo no sólo por sus propias características sino porque los sujetos sienten una cierta insatisfacción o son críticos de los valores y roles de su entorno cristiano secularizado.

El modo en que se produce la conversión, si a partir del establecimiento de una continuidad o de una ruptura con la situación biográfica anterior, es el punto central de indagación de Wohlrab-Sahr (1999) que compara casos relevados en Estados Unidos y Alemania. Ese trabajo recorre los distintos modos de adoptar el Islam a partir del sistema de referencia previo de los conversos. Si bien nuevamente tienen centralidad las razones dadas por los sujetos, este estudio se interesa más por analizar el papel de la conversión en las historias de vida de los entrevistados, intentando dilucidar qué problema o crisis resuelve la conversión y cómo esa experiencia de vida se expresa a través de símbolos religiosos. El resultado del análisis permite situar lo que para la autora serían dos lógicas de adoptar el Islam: el "sincretismo" y la "batalla simbólica". La primera señala más una forma de alternación, combinando ideas de las antiguas pertenencias con las 
nuevas, es decir, señalando continuidades y cambios menos radicales; la segunda, implica la conversión posterior a crisis y rupturas. En el primer caso los sujetos esgrimen elementos comunes entre su religión pasada y el Islam; por ejemplo, es el caso de mujeres entrevistadas casadas con musulmanes, donde la conversión más que una ruptura expresa las nuevas circunstancias de vida en tanto esposas y miembros de una familia musulmana. La batalla simbólica, en cambio, es un proceso de transformación donde el rechazo por un estado anterior aparece con mayor nitidez, ese rechazo puede referirse a varios aspectos, desde las reglas de moralidad o rol de los géneros en la sociedad o la pertenencia a una subcultura socialmente subalternizada. Desde ese punto de vista, la conversión al Islam también permite dramatizar problemas de desintegración social y solucionar problemas individuales. Este enfoque termina reafirmando conocidos argumentos de cualquier estudio sobre conversiones, sin ofrecer una comprensión específica de la conversión al Islam, pues evidentemente los procesos de rupturas y continuidades pueden encontrarse en la mayoría de los procesos de adopción de otras religiones. El único argumento que en este abordaje parece pretender explicar la elección por el Islam se relaciona con lo que podríamos denominar "factor otredad". Así, una religión con mayor otredad permitiría simbolizar una mayor distancia social y su adopción denotaría un problema de integración del medio previo, creando una distancia social más marcada con el contexto que se rechaza. Evidentemente, se trata de un argumento derivado de las representaciones sobre el Islam preponderantes en la sociedades estudiadas.

Otros estudios harán hincapié en buscar factores de atracción, una pregunta por aquellas propiedades o características del Islam que atraen a los individuos. A modo de ejemplo citamos el estudio de Sultán sobre convertidos en Suiza, donde se trata de indagar qué valores y estilos de vida son destacados por los que ingresan en la religión. En el discurso de algunos convertidos la atracción aparece referida a que el Islam provee seguridad, otorga centralidad a la familia, es claro en sus reglas que abarcan todos los aspectos de la vida, tiene firmeza de principios, ofrece un modelo de justicia política y un sistema filosófico. Este conjunto 
padronizado de factores de atracción constituiría los diferentes aspectos del Islam entre los que se mueven los convertidos y aquellos que eligen uno de esos aspectos podrán ser críticos respecto de los otros (SULTÁN, 1999, p. 332). A la fase de atracción le seguiría una fase que la autora denomina "reformulación", donde puede haber conflicto con aquello que originalmente atrajo al sujeto, situación que en algunos casos lleva a confirmar patrones de comportamiento previos y, en otros, a rechazarlos.

Según esta literatura la conversión se explica en gran medida por una búsqueda estimulada por la insatisfacción de los sujetos con su entorno previo, en un contexto visto como post-cristiano, secular o incluso calificado por los convertidos como materialista, consumista, carente de valores, etc. Los individuos encontrarían en el Islam una creencia más clara y firme, a la que llegarían a través de caminos intelectuales o filosóficos, matrimoniales, económicos, por la mera curiosidad, por la atracción que ejerce una noción fuerte de comunidad universal y lo harían, o bien en la forma de una ruptura, por lo general seguida a una crisis, o estableciendo continuidad con sus creencias anteriores y encontrando en el Islam un perfeccionamiento de las mismas o una solución ante una desintegración biográfica. En todos estos trabajos las razones dadas por los actores constituyen las razones de la conversión y el analista se limita a ordenar y agrupar las representaciones para lograr así construir un patrón común.

Por último, podemos considerar un abordaje que comparte los presupuestos anteriores pero intenta establecer una tipología de la conversión presentando un modelo basado en casos de Francia y Estados Unidos, pretendiendo ir más allá de esos referentes empíricos. El análisis de Daynes (1999) enmarca el tema en una problemática identitaria social y colectiva, elaborando tipos ideales que articulan referencias fundamentales presentes en las representaciones de los convertidos con un padrón de "modos de identificación". La autora afirma que la conversión articula cuatro referencias fundamentales en las representaciones de los 
individuos: 1) La referencia a la tradición (cuyos polos son el rechazo y la aceptación); 2) referencia a la comunidad (con los polos de individualismo y comunitarismo, a los que se corresponden un énfasis más espiritual y confesional respectivamente); 3) referencia a la etnicidad (pudiendo ser leve o intensa) y, 4) referencia a la sociedad (con los polos de integración y rechazo). A su vez los modos de identificación podrían reducirse a cuatro: a) El Islam como otro monoteísmo; b) como culminación de un camino espiritual, c) como forma de recuperar las raíces y d) el Islam como oposición a la opresión. Bien, esta tipología permite entonces considerar cada uno de los modos de identificación con variaciones respecto de esas referencias a la tradición, a la comunidad, a la etnicidad y a la sociedad. Por ejemplo, entre aquellos entre los que es central la noción de seguir el "Islam como otro monoteísmo" la referencia a la tradición tiene el carácter de aceptación, convertirse es inscribirse en una línea de legitimidad monoteísta; la referencia a la comunidad será limitada, ya que la conversión se realiza para Dios más que en referencia a un grupo; el apelo a la etnicidad es débil, dado que ese tipo de conversos tenderían a considerar al Islam como una religión universal y compararlo con su pasado cristiano, considerando al Islam como un mejor cristianismo o una versión depurada; por último, la referencia a la sociedad tiende hacia la integración o lucha por el reconocimiento, aun en el caso de visiones críticas de la sociedad occidental. De acuerdo a cada modo de identificación existirá un contenido disímil respecto de las cuatro referencias, pudiendo establecerse una tipología ideal que reproducimos a continuación: 
Tabela 1 - Tipología de los modos de identificación al Islam

\begin{tabular}{|c|c|c|c|c|}
\hline & $\begin{array}{c}\text { Otro } \\
\text { monoteísmo }\end{array}$ & $\begin{array}{c}\text { Culminación } \\
\text { camino } \\
\text { espiritual }\end{array}$ & $\begin{array}{c}\text { Medio de } \\
\text { retornar a } \\
\text { raíces }\end{array}$ & $\begin{array}{c}\text { Oposición a la } \\
\text { opresión }\end{array}$ \\
\hline $\begin{array}{c}\text { Referencia a } \\
\text { la tradición }\end{array}$ & Aceptación & Aceptación & Reinvención & Rechazo/aceptación \\
\hline $\begin{array}{c}\text { Referencia a } \\
\text { la comunidad }\end{array}$ & Limitada & Media & Intensa & Fuerte \\
\hline $\begin{array}{c}\text { Referencia a } \\
\text { la etnicidad }\end{array}$ & Débil & Débil & Fuerte & Variable \\
\hline $\begin{array}{c}\text { Referencia a } \\
\text { la sociedad }\end{array}$ & Integración & Integración & Rechazo & Rechazo \\
\hline
\end{tabular}

Fuente: DAYNES, 1999, p. 318.

Aunque en el contexto latinoamericano existen pocos trabajos específicos sobre la conversión al Islam, podemos ponerlos en diálogo con estas tipologías. Los patrones descubiertos paralelamente en nuestras investigaciones, con matices y especifidades contextuales, parecen en parte compatibles con los que señalan los trabajos antes mencionados, a excepción del modo de identificación del Islam como otro monoteísmo, que si bien puede ser resaltado en el discurso de los actores, no parece aparecer como un modo de identificación determinante entre los convertidos de Brasil o Argentina. En el marco de una caracterización general del conjunto de miembros de la comunidad musulmana de Rio de Janeiro (Montenegro, 2000), que posteriormente retomaré para el caso argentino -y donde distinguía tres subgrupos: musulmanes de nacimiento, diáspora del Islam y convertidos- elaboré una clasificación de los conversos teniendo en cuenta tres caminos hacia el Islam y dos tipos de procesos de ruptura con experiencias biográficas anteriores, que aparecían como factores explicativos en algunas trayectorias de conversión. La estrategia metodológica que había empleado fue la 
observación participante de larga duración, con menos énfasis en la realización de entrevistas y mayor seguimiento de las trayectorias individuales en relación con el proyecto identitario que en ese entonces caracterizaba a la comunidad en cuestión. En aquel momento afirmaba que existían conversos que habían seguido:

1) Camino intelectual, éstos eran lectores ávidos de cuestiones relacionadas con la historia civilizacional árabe o con la realidad política del mundo del Islam, llegaban a la comunidad con cierto bagaje de conocimiento, casi todos esos miembros poseían algún grado de educación superior, profesores de historia, estudiantes de economía, historia antigua, aspirantes a estudios diplomáticos, autodidactas, etc.

2) Caractericé un segundo grupo como “admiradores” de la civilización del Islam, incluí en esa clasificación a personas cuyo interés en el Islam se había originado a partir de viajes frecuentes, básicamente de turismo, por países de Medio Oriente o del Norte de África. Éstos se mostraban interesados en la lengua árabe, como instrumento para utilizar en futuros viajes, y en la adquisición de conocimientos más profundos sobre la “cultura islámica”, con la cual habían tenido oportunidad de convivir en sus experiencias de viajes. Aquí el Islam aparecía representado como un "producto exótico" y quienes seguían este camino demostraban interés en la culinaria árabe, las vestimentas y los objetos de arte propios de la cultura árabe musulmana. Entre éstos sólo algunos completaban su conversión.

3) Un tercer conjunto buscaba el aspecto místico del Islam, el sufismo, sobre el cual tenían algún conocimiento autodidacta o a través de prácticas místicas de otras vertientes religiosas o seculares (meditación, etc.), la mayoría permanecía a pesar de que esa institución no ofrecía un espacio dedicado a esas prácticas, reconfigurando su adhesión al modelo preponderante del contexto institucional. 
Al tener en cuenta que estos caminos hacia el Islam habían sido organizados en función de experiencias, necessidades y estratégias particulares de los sujetos, distinguí dos experiencias de ruptura con el medio anterior que también funcionaban como motor de conversiones o como reconfiguración de antiguas adhesiones: a) Mujeres que habían formalizado un noviazgo con hombres musulmanes, entre las cuales la conversión al Islam o el hecho de frecuentar la mezquita había comenzado a formar parte de un nuevo proyecto de vida, aun cuando eran conscientes de que no era necesario ser musulmana para casarse con un musulmán; b) la segunda experiencia de ruptura estaba representada por lo que llamé desilusión política. Algunos de esos miembros reconocían haber adherido a ideas "de izquierda", haber creído en la posibilidad de un cambio radical en la sociedad brasileña, al mismo tiempo que manifestaban desilusión por la experiencia de fracaso de ese proyecto. En esos casos la pérdida de la utopía parecía canalizada por la propia idea de reforma del sistema islámico, como un nuevo proyecto en el cual creer y por el cual trabajar (MONTENEGRO, 2000, p. 46-52).

Es interesante notar que trabajos posteriores en otras comunidades de Brasil encontraron patrones similares. Uno de los más exhaustivos, ya que aborda exclusivamente el tema de la conversión, es el de Ramos (2003) que, sin establecer una tipología, y basado en el caso de los convertidos de la comunidad musulmana de São Bernardo do Campo, demuestra que éstos, con diversos antecedentes religiosos y determinado perfil sociológico en lo que hace a nivel educativo, de ingresos, etc., llegan al Islam a través de casamientos, de participación o militancia en movimientos de concientización política (movimiento negro o ideas de izquierda) y por inquietudes intelectuales o artísticas. Todos comparan su universo de creencias anterior estableciendo rupturas o continuidades y se acercan por amistades, colegas de trabajo, a partir del estudio de la lengua árabe o, incluso, por la curiosidad suscitada luego del 11S. En un enfoque que considera distintas comunidades de Brasil, Pinto reconoce 4 
patrones similares: conversión matrimonial, los que se convirtieron para casarse o por estar casados con musulmanes; conversión afectiva, aquellos que conocieron o adhirieron al islam a partir de relaciones de admiración o amistad con musulmanes con los cuales conviven en ambientes de trabajo, estudio o tiempo libre; conversión intelectual, que generalmente está ligada a miembros de clase media o estudiantes universitarios que se interesan en conocer mejor el I slam y conversión ideológica, que incluye ex militantes de partidos o movimientos de izquierda que, al desilusionarse con los rumbos de la izquierda en Brasil ven en el Islam una nueva forma de tercer mundismo que incluye la lucha contra el imperialismo en su mensaje religioso (PINTO, 2010, p. 212-213).

A excepción de la motivaciones que denominé como relacionadas a la búsqueda, no siempre posibilitada por la oferta institucional en Brasil, de los aspectos místicos del Islam y de éste como un producto exótico de consumo cultural, los patrones detectados posteriormente y en otras comunidades de Brasil, confirman la clasificación de caminos de la conversión realizada en relación a la comunidad de Rio de Janeiro. Por lo cual tal vez podamos concluir que el camino intelectual, el vinculado a los casamientos, el de la vía militante, ya sea en términos de desilusión o reconversión política, son elementos constantes en lo que respecta a las trayectorias de los conversos. En lo que se refiere a los modos de llegar a la religión también existe un acuerdo en considerar que las relaciones interpersonales (amistad, trabajo, etc.) que permiten conocer la religión, así como los eventos amplificados por los medios de comunicación, como el 11 de septiembre10, o el auge de ficciones de TV, literarias o de cine, en algunos casos funcionan como estímulo de la curiosidad por el Islam entre aquellos que no tienen ascendencia árabe.

\footnotetext{
${ }^{10}$ Respecto del 11 de septiembre como activador de la curiosidad hacia el Islam, este evento aparece en el discurso de los informantes entrevistados por Ramos (2013, p. 84) y, en el caso de Pinto aparece mencionado como un factor de menor incidencia que la difusión de la telenovela "El Clon" (PINTO, 2010, p. 209).
} 


\section{Lenguajes de la conversión en Argentina}

Basándonos en la evidencia etnográfica de distintas comunidades en Argentina, podemos ver que respecto a la conversión se repiten algunos rasgos de los casos de Brasil, pero existen también algunas especificidades locales que abordaremos en un sentido general ya que estamos ante más semejanzas que diferencias respecto a los patrones ya descubiertos. En la mayoría de los contextos institucionales es posible mantener la caracterización de la membresía general construida para el caso de Brasil: musulmanes de origen o nacidos en la religión, diáspora del Islam y convertidos (MONTENEGRO, 2000, p. 40). Los musulmanes de origen son aquellos argentinos descendientes de inmigrantes árabes musulmanes de Siria o Líbano, por lo general de tercera generación, entre los que encontramos sunitas, shiitas y alauitas. A diferencia de Brasil, el dominio de la lengua árabe difícilmente opera como diacrítico para establecer fronteras entre estos musulmanes de origen y los conversos púes, salvo excepciones, la mayoría de los descendientes no tiene fluencia en el idioma ${ }^{11}$. Lo que llamamos diáspora del Islam está compuesta por musulmanes extranjeros que por estudio o trabajo pasan temporadas en el país y frecuentan circunstancialmente las instituciones y por algunos inmigrantes recientes que circulan entre instituciones o se acercan a las comunidades con distinto nivel de compromiso en las prácticas o que, como el caso de los senegaleses de la cofradías Muridiyyah y Tijaniyyah (ZUBRZYCKI y AGNELLI, 2009, p. 145), tienen sus propios espacios religiosos y frecuentan ocasionalmente algunos centros islámicos como el CIRA o el Centro Islámico Rey Fahd. Los conversos son aquellos que se acercan al Islam sin tener una

\footnotetext{
${ }^{11}$ Fuera de la llegada de inmigrantes individuales, en Argentina no hubo una renovación marcada de los contingentes migratorios, a lo que se suma el factor fuertemente homogeneizante que, en el proyecto de construcción nacional, tendió a la integración lingüística obligatoria de los inmigrantes al español. Estudios históricos como el de Akmir (1990, p. 272-326) demuestran que la pérdida del idioma de origen se da ya en las segundas generaciones. En distintas comunidades pude comprobar que, salvo algunos shaykhs argentinos que adquirieron la lengua ya adultos a partir de estudios en el exterior o de "enclaves culturales" como la localidad de La Angelita, el uso del árabe es prácticamente inexistente entre los descendientes. Esta situación del presente tal vez pueda variar por la creación de escuelas árabes que hoy permiten la socialización lingüística de nuevas generaciones de descendientes, como es el caso del Colegio Argentino-Árabe Omar Bin Khattab, dependiente del Centro Islámico de la República Argentina, creado en el año 1991, y de carácter confesional desde 2009, y el colegio Rey Fahd del Centro Cultural Islámico Custodios de las Dos Sagradas Mezquitas Rey Fahd, también confesional, ambos en la ciudad de Buenos Aires.
} 
ascendencia que los relacione con los grupos inmigrantes originalmente portadores de la religión.

Varios de los patrones y tipologías de la conversión mencionados en párrafos anteriores combinan o entremezclan factores de atracción atribuidos al Islam (ej. reglas claras), tipos de camino hacia la conversión (ej. intelectual, político) y formas a través de las cuales los sujetos llegaron a la religión y sus espacios institucionales (casamiento, amistad, conocimiento a través de sucesos mediáticos, cursos, etc.). Si partimos de que todos los modelos de conversión son construidos a partir de las razones dadas por los sujetos en relación con el proceso o del análisis de las narrativas biográficas, tal vez sea más apropiado considerar que dentro de los discursos de los convertidos la alusión a las motivaciones y los caminos que los condujeron hacia el Islam se expresa en la forma de lo que podríamos denominar lenguajes de conversión ${ }^{12}$. Al analizar las narrativas sobre la conversión entre argentinos encontramos un conjunto de lenguajes disponibles en los cuales los sujetos localizan su proceso, estos lenguajes conforman un repertorio limitado que permite insertar las biografías en discursos contextualmente legítimos (SOMMERS, 1994, p.614). Esa cierta estandarización de los lenguajes en que inscribir la conversión parece generada por la interacción entre conversos que recorren trayectorias similares hasta llegar al Islam, por la circulación de "ideas fuertes" en los espacios institucionales, por ejemplo, la noción del Islam como una religión lógica y clara y por un contexto cultural más amplio que valoriza la “intelectualización” y la "politización” en los espacios de clase media a la cual pertenecen la mayoría de los conversos ${ }^{13}$. Esto significa que existen una serie de representaciones "habilitadas" para construir el lenguaje de la conversión. Consideramos que las narrativas que conforman esos lenguajes no reflejan exactamente las motivaciones que conducen a la conversión, las cuales estarán

\footnotetext{
${ }^{12}$ Elegimos condensar en un conjunto de lenguajes los caminos de la conversión narrados por el conjunto de entrevistados, a diferencia del análisis de los modos de adhesión entre musulmanes de origen donde apelamos a ejemplos representativos.

${ }^{13}$ Sin pretender reificar los imaginarios y mitologías nacionales cruzados que, a veces reforzados también por discursos académicos, suponen a Brasil como una sociedad sincrética y con fluidez de creencias y a los sectores medios de la sociedad argentina como más secularizados, cuando no psicoanalizados, es probable que la prevalencia de ciertos lenguajes de la conversión se relacione con las diferencias culturales que permean los espacios religiosos de ambas sociedades. Para un análisis interesante del uso del concepto de conversión en Brasil y Argentina que refiere a la auto-imagen de ambas sociedades, Ver FRIGERIO, 2012.
} 
vinculadas a procesos más complejos e individualizados, que escapan a la mayoría de las investigaciones que no consideren detalladamente los aspectos biográficos de los conversos. Tampoco podemos asimilar los motivos de la conversión con las formas en que los sujetos llegaron a la religión, por ejemplo, que hayan sido atraídos por las noticias sobre el Islam en los medios de comunicación no nos permite inferir que esto haya motivado la conversión. Refiriéndonos a predominios, y nunca a formas exclusivas, podemos decir que en los casos aquí analizados el lenguaje intelectual para narrar la conversión y el lenguaje espiritualista son aquellos que prevalecen, asociándose a veces el lenguaje político generalmente como añadido al intelectual.

Entre aquellos que narran su conversión en un lenguaje intelectual, encontramos referencias al estudio, análisis, búsqueda de cursos, reflexión, lecturas, encuentro con determinados libros, preguntas a líderes religiosos, interés por la comparación de religiones, grupos de estudio y un acercamiento gradual y reflexivo a los espacios institucionales. Estos discursos también tienen en común el hecho de interpretar la elección religiosa en término de una búsqueda racional, con poca o ninguna alusión a crisis de vida o estados afectivos y con más referencia a crisis sociales o de valores morales. En ninguno de estos casos la conversión fue relatada como un hecho súbito, al contrario, fue presentada como el crecimiento lento de una idea, madurada por la vía de la reflexión. El lenguaje espiritualista prevalece entre los que dijeron acercarse buscando aspectos místicos, como el sufismo. Éstos incluyen en su relato la alusión a búsquedas anteriores de consumo espiritual, prácticas, formas de bienestar corporal, transformaciones del espíritu, estabilidad a partir del reconocimiento de un guía espiritual, descubrimiento de nuevas sensibilidades y superación de "falsas angustias", dietas alternativas, etc. En este conjunto encontramos la mención a crisis de vida, deseos de superación y "liberación de falsas ataduras", de relación directa con Dios y armonía con el entorno. La idea de reconfiguración del yo tiene aquí centralidad, así como la explicitación de su multiplicidad de planos (físicos, espiritual, sensorial). El 
acercamiento a asociaciones sufíes aparecía como finalización de un recorrido espiritual previo o luego de un conjunto de experimentaciones. Entre algunos la conversión había conducido a frecuentar mezquitas o centros, otros permanecen exclusivamente en los círculos del sufismo o haciendo coexistir estas prácticas con otras. El lenguaje espiritualista no excluye al intelectual, pero parece subsumirlo a un espacio subordinado a la ampliación espiritual. Así, algunos convertidos decían haber iniciado lecturas históricas sobre el Islam y haberse interesado en el universo geopolítico del mismo para comprender mejor su dimensión global.

Por otro lado, entre los que narraron su conversión en un lenguaje político se tornó central el hecho de esgrimir una continuidad o ruptura ideológica con ideales seculares, respectivamente transformados en utopías religiosas o invalidados a través de ellas. Ese lenguaje político no necesariamente proviene de la reconfiguración religiosa de "ideas de izquierda”, muchas veces proviene del trazado de compatibilidades entre los valores políticos que estructuraron una militancia pasada y los valores religiosos que estimulan una adhesión que resulta coherente con ese pasado. Lo que observamos es que el lenguaje político no aparece como exclusivo al narrar la conversión, en algunos casos lo encontramos como añadido al lenguaje intelectual. Al mismo tiempo, supone una ampliación de los escenarios de preocupación política anteriores, al incluir las problemáticas de Medio Oriente y del mundo árabe islámico. El lenguaje exotizante que estructura algunos de los discursos de los convertidos puede solaparse con los anteriores y aparece más superpuesto con el espiritualista, pero resalta el interés por una aproximación a la cultura que se supone que es portada por la religión y básicamente alude a sus signos externos como el vestuario, la culinaria, los viajes, amistades diferentes, conformando un panorama más culturalista que religioso. Sin embargo, entre los convertidos que frecuentan instituciones más tradicionales, como las creadas por inmigrantes o sus descendientes, encontramos una escasa presencia del lenguaje exotizante donde la aproximación haya estado estimulada por una admiración previa de la civilización islámica adquirida en viajes o que lo asocien a un producto exótico que incluye formas de consumo. Lo que observamos 
es que ese segmento de "admiradores" de la civilización islámica atraídos por representaciones de exotismo se da hacia el interior de los conversos a algunas vertientes del sufismo donde, por otro lado, también encontramos quienes adicionan un lenguaje intelectual menos preponderante. Si el discurso de los conversos al sufismo parece incorporar en distintos niveles los lenguajes intelectuales, políticos ${ }^{\mathbf{1 4}}$ y exotizantes, como dependientes del espiritualista, tal vez se explique porque actualmente constituye uno de los espacios más dinámico de conversiones. Su presencia y expansión en Argentina es un fenómeno singular y aún no estudiado, con antecedentes de algunos líderes y grupos existentes en la década del $70^{15}$ y las ya mencionadas filiales de la orden Naqshbandi, Yerrahia y grupos autonomizados.

Así, si bien los motivos de la conversión pueden ser tan variados como las formas a través de las cuales los individuos llegan efectivamente a los espacios religiosos propiamente dichos, lo que parece seguir cierto patrón es el uso por parte de los sujetos de un lenguaje preponderante para narrar su conversión, el cual no es excluyente de otros lenguajes.

Por último, la conversión a través de la construcción de un nuevo proyecto de vida a partir de casamientos con musulmanes representa un fenómeno protagonizado por algunos pocos individuos $\mathrm{y}$, en los casos que relevamos, la opción por el casamiento con un musulmán generalmente fue posterior al ingreso a la nueva religión. La conversión narrada en un lenguaje político o ideológico que resulta de una desilusión de militancias anteriores es menos frecuente que la que concilia la preservación de una militancia anterior, donde la nueva adhesión religiosa es vista como compatible con posturas anti-imperialistas, de igualdad social y de participación política simultánea en agrupaciones seculares. Localmente no existe la posibilidad de apelar a un lenguaje de conversión como

\footnotetext{
${ }^{14}$ También relevamos casos de individuos, que incluso ocupan espacios administrativos en grupos sufíes, con trayectorias de militancia política anterior que reconfiguraron su ideología en un lenguaje espiritualista.

${ }^{15}$ La figura del shaykh argentino Alí Al-Husainí es fundamental para comprender el desarrollo del sufismo a partir de la década del 70 , más allá de los grupos que posteriormente llegan a la Argentina.
} 
retomada de raíces o reivindicación en torno a una identidad negra, como en Brasil entre los que reinventan el linaje de un Islam negro o en Estados Unidos en variantes del Islam etnicizadas. Como veremos, el discurso de retomar raíces se da entre descendientes de “árabes” que reasumen una religión considerada como portada por sus antepasados ${ }^{16}$.

\section{Modos de adhesión entre musulmanes de origen}

Como dijéramos anteriormente, las formas de adhesión de los musulmanes de origen constituye un aspecto poco abordado en el estudio de las comunidades musulmanas. En general porque hasta el momento se han considerado los proyectos identitarios de modo más institucional y grupal, las orientaciones doctrinales y sus dinámicas transnacionales y la relación entre musulmanes árabes y convertidos al interior de distintas comunidades ${ }^{17}$. Es por ello que en numerosos trabajos los musulmanes que componen las comunidades por haber heredado la religión aparecían como la membresía natural y constante, a la que se agregaban los convertidos. En distintas instancias de trabajo de campo fui conociendo e indagando sobre las trayectorias de musulmanes de origen, comprobando que en muy pocos casos sus biografías religiosas dentro del Islam habían sido lineales. Para abordar ese aspecto fue necesario prestar atención a las trayectorias individuales, más allá de los contextos institucionales que los sujetos frecuentaban en el presente. Tomando como ejemplo algunos casos representativos es posible elaborar una tipificación que, no obstante, no agota la diversidad. Me refiero aquí a argentinos musulmanes que practican su religión en forma individual o comunitaria, descendientes de segunda, tercera o cuarta generación de inmigrantes árabes musulmanes y que elaboran distintas representaciones sobre su adhesión al Islam. Así, mientras que para algunos el Islam aparece como un

\footnotetext{
${ }^{16}$ De todos modos, en los contextos locales difícilmente encontremos la identificación de descendientes como "árabes", sirios o libaneses, todo descendiente aunque sea de primera generación será considerado y se referenciará a sí mismo como argentino, siendo más corriente el reconocimiento del grupo de pares de descendientes como "paisano", una categoría poco específica utilizada también entre judíos.

${ }^{17}$ Ver MONTENEGRO, S. y BENLABBAH, F. 2013.
} 
legado cultural que debe preservarse, para otros el discurso de la "opción" o la "elección", aun habiendo nacido en la religión, parece ocupar un lugar central. Para otros, esa herencia cultural puede ser experimentada como una obligación que torna conflictiva las relaciones entre las expectativas de sus círculos de sociabilidad y sus deseos personales. Otros, suponen estar reasumiendo una identidad religiosa de origen y consideran el retorno como una conversión o como un despertar. El tránsito entre doctrinas y vertientes del Islam también aparece en la biografía religiosa de algunos.

\section{a) Preservar un legado cultural}

Algunos musulmanes que dijeron haberse mantenido estables en su adhesión religiosa afirmaron que se trataba de un proceso natural, que la religión formaba parte de su educación familiar y que era importante evitar que se pierda la tradición en las nuevas generaciones. Por ejemplo, Camilo, que forma parte de una familia sunita, afirmaba que la suya era una de las pocas que había logrado preservar la religión y que si aquellos que llegaron en la misma época que sus padres lo hubiesen hecho "hoy Argentina tendría el triple de musulmanes". Omar, en cambio, dice que fue su abuelo el que le insistió para que "tome en serio la religión", cosa que sus tres hermanos no habían hecho, "desentendiéndose de sus raíces”. Amado, de una familia shiita del noroeste del país, narra que tanto sus padres, como él y sus hermanos y ahora sus hijos se formaron en un ambiente religioso que "no los privó de convivir con todo tipo de gente, sin que esto altere ser fieles a nuestra tradición". Otros, lamentaron que a diferencia de sus casos particulares muchas familias antiguas hayan perdido la religión de origen. Todos nuestros entrevistados tenían en común el provenir de familias que habían conservado las tradiciones religiosas de origen y que han participado en la creación y organización de centros islámicos e instituciones del país. Muchos de ellos hoy ocupan espacios de gestión en las mismas instituciones en las que participaron sus 
padres o abuelos y han contribuido a mantenerlas y ampliarlas. Entre ellos la identidad religiosa suele estar asociada a una identidad árabe de origen, lo que explica su participación en algunos espacios institucionales del asociacionismo árabe, - compartiendo este espacio con descendientes de árabes de otros credos religiosos. En general, la religión fue asociada a un legado cultural que debe ser preservado, transmitido y sustentado a través de instituciones, cuestionarlo sería optar por la pérdida de raíces. Entre estos musulmanes el discurso preservacionista es el que prevalece, junto a la idea de la adhesión como un proceso natural, lógico e imposible de disociar de una cultura de origen. En estas representaciones el Islam aparece como una religión comunitaria, donde las familias integran una comunidad más amplia de descendientes de inmigrantes.

\section{b) Optar por la tradición}

Otros musulmanes observantes destacaron los conceptos de "opción” y “elección” para conceptualizar su adhesión. Cuestionando la noción de la religión como herencia o legado cultural afirmaron que sólo la elección sostiene la creencia. Veamos uno de estos ejemplos, al momento de conocer a Hassan él era shaykh de un centro islámico de los más antiguos del país, aquellos fundados en las primeras décadas del siglo XX por los inmigrantes. Se destacaba por su amplio conocimiento religioso, adquirido en centros de formación religiosa internacionales de orientación sunita $\mathrm{y}$, al mismo tiempo, por ser un shaykh argentino joven e interesado y familiarizado en la realidad local. Siendo musulmán de nacimiento pertenecía a una familia de origen sirio del norte del país. Sin embargo, cuando se refiere a su pertenencia religiosa resalta que la misma es por opción y no por herencia, es por elección y no por mandato familiar, costumbre o para conformar a su entorno. Después de los veinte años, y sintiéndose cómodo como musulmán, decidió probar su fe. Con ese objetivo conoció los preceptos de distintas religiones, conversó con pastores, sacerdotes y hasta rabinos, visitó templos y lugares de culto, quería ver si alguna de esas otras religiones era capaz de superar las certezas que le proporcionaba el Islam. Su recorrido culminó con 
una afirmación del carácter convincente que para él tenía el Islam, con el deseo de realizar estudios religiosos y dedicarse a conducir a las comunidades. Luego de consumada esta “elección”, Hassan partió para un país de Medio Oriente donde estudió varios años, prosiguiendo su formación en una importante institución del norte de África. A su regreso, luego de más de una década, destacándose por los estudios y títulos obtenidos, se desempeñó como shaykh en una institución de Argentina, pero al cabo de unos años Hassan dejó de ejercer como shaykh y ahora es un musulmán "independiente”, dispuesto a transmitir su conocimiento a quien lo busque.

Para Mohammed, que dice estudiar por su cuenta, "tener conciencia de practicar por elección es lo único que preserva viva la religión”. Él supone que algunos inmigrantes antiguos creyeron que, como en sus aldeas de origen, la religión se transmitiría naturalmente de padres a hijos y que eso produjo musulmanes nominales: "En Argentina o en cualquier país no islámico tenés que elegir por convicción, por más que te hayan criado con los valores religiosos". Como en estos ejemplos, algunos otros entrevistados explicaron su adhesión como una elección, mencionaron la pluralidad de opciones religiosas de Argentina, posicionando al Islam como una de esas creencias. En estos casos el acento estaba puesto en la reflexividad individual, más que en una comunidad de origen y destino, en la capacidad personal de discernir entre opciones y adherir conscientemente a la tradición familiar.

\section{c) La adhesión como reasunción: "conversión" y despertar}

Ocupando un espacio liminar entre los musulmanes de origen y los conversos encontramos a aquellos que explican su adhesión al Islam como un proceso de retorno, redescubrimiento o reasunción de una religión a la que sienten que pertenecen en virtud de un legado cultural. Al relatar este proceso algunos decían haber descubierto que un abuelo o bisabuelo profesaba la religión y que 
ésta no había sido seguida por sus padres, esto había desatado una curiosidad por sus raíces y un acercamiento a través de la búsqueda de conocimiento, la visita a instituciones o la conversación con algún skaykh. Al mismo tiempo, todos relataban haber emprendido una búsqueda de información sobre ese origen familiar, su lugar exacto de origen, fotos o documentos que puedan ayudar a reconstruir su historia religiosa. Ahora bien, algunos se representaban esta reasunción como análoga a un proceso de conversión y otros como un proceso de descubrimiento. Por ejemplo, Jamal es “descendiente remoto de libaneses", sus bisabuelos llegaron a Buenos Aires pero sus abuelos y padres nacieron en Argentina y no conservaron costumbres culturales o religiosas de origen. Nunca tuvo muy claro cuál era la religión que profesaban sus ancestros inmigrantes y cuando se interesó por el tema fue encontrando algunas pistas que lo llevaron a pensar que se trataba de una familia musulmana. Hace menos de una década se acercó a la mezquita Rey Fahd en Palermo para interiorizarse en los contenidos del Islam y posteriormente se inscribió en el curso de lengua árabe. Según su relato, el hecho de portar un apellido árabe hizo con que naturalmente se lo considerase en el nuevo entorno como un "musulmán que vuelve a la práctica". No obstante, Jamal se considera y se presenta a sí mismo como un convertido. Por un lado, narra los momentos de su trayectoria de vida estableciendo el hito temporal entre hechos que ocurrieron "antes o después de convertirme". Por otro lado, expresa que en algunos espacios religiosos que fue frecuentando el hecho de ser tomado de antemano como un musulmán dificultó o hizo más lento su aprendizaje de los principios de la religión. En ocasiones dice que sentía vergüenza al preguntarle a otros musulmanes cosas que éstos suponían que él sabía y, en otras, al no tener respuestas para preguntas que le hacían los conversos suponiendo justamente que él las tendría. En menos de un año hizo su shahada en una institución "donde era menos conocido" y no se preocupó mucho por anunciar el hecho en otros espacios donde "siempre había sido tratado como musulmán”. Jamal que hoy tiene 38 años dice que es el único religioso de una familia agnóstica que "acepta sin problemas mi elección”. 
Otro ejemplo similar es el de Ahmed, que estudia ciencias sociales en una universidad de una ciudad del interior del país. Aunque sus abuelos vinieron de Siria, de una "región de musulmanes", el tema de la religión no se mencionaba demasiado en su casa. Cuando comenzó a indagar en sus "raíces religiosas" descubrió algunos libros en casa de familiares, coranes y otros indicadores del origen musulmán de sus abuelos. Para informarse comenzó a frecuentar distintas instituciones que no siempre le resultaron acogedoras y se mostró más interesado por conversar con shaykhs y dejarse guiar por ellos. En su discurso también el momento de la "conversión" es colocado como hito, mencionando hechos que ocurrieron "antes de convertirme" o "después de convertirme”. Actualmente su adhesión al Islam implica un compromiso en la difusión tanto de la cultura árabe como de la religión musulmana. Ahmed planea viajar a Siria a la región de sus ancestros, toma clases particulares de árabe y, demostrando conocer las distintas vertientes de la religión musulmana, dice haber adoptado el Islam sunita, a pesar de haber comprobado que sus abuelos eran alauitas.

Si bien tanto Jamal como Ahmed en el entorno de los musulmanes de origen eran vistos como reasumiendo una identidad ancestral por ser descendientes de musulmanes, ambos esgrimieron haber experimentado su adhesión como un proceso de conversión que incluyó una ruptura con el pasado y la finalización de una búsqueda de raíces, de descubrimiento de un origen que debía ser rescatado.

No todos los que asumen su adhesión como la reasunción o retomada de un legado cultural piensan su trayectoria en términos de conversión. Por ejemplo, tres descendientes de tercera generación de árabes musulmanes sunitas nos relatan que fueron visitados por misioneros de la Jamaat Tabligh en el año 2008 y que esto los condujo a un "despertar", ya que su religiosidad estaba dormida. Hoy dicen que "se inspiran en el shiismo" y no reconocen pertenencia institucional, decidieron ser musulmanes por cuenta propia, pero creen que el contacto con los 
misioneros cuya doctrina hoy critican fuertemente, sirvió como un disparador para "volver". Antes de ese hecho se definían como no creyentes, sus padres se habían asimilado a la cultura católica, afirman que transitaron juntos este retorno y hoy intercambian materiales de lectura e información religiosa.

\section{d) El tránsito como intensificación de la adhesión}

La movilidad dentro de distintas doctrinas y concepciones del Islam a lo largo del curso de vida también forma parte de los modos de adhesión, es lo que denomino tránsitos intra-islámicos ${ }^{18}$. De las trayectorias relevadas, cuyas direcciones son variadas, tomaremos el ejemplo de la de Kemal, que a diferencia de las demás incluye un triple tránsito. Él es un líder religioso de una comunidad del interior argentino, estudió en un importante centro de formación religioso internacional, creó organizaciones, condujo comunidades en otros países. Nos relató el camino desandado por él y un conjunto de antiguos compañeros hasta llegar a su actual adhesión al Islam shiita. En su caso particular, había nacido en un medio de otra vertiente islámica y en su adolescencia comenzó a recibir la orientación religiosa necesaria para ser un futuro shaykh, pero conoció una serie de personas que le mostraron otros caminos. Así, fue discípulo de uno de los más reconocidos introductores del sufismo en la Argentina y permaneció algunos años en ese grupo. A mediados de la década del 80 conoció a un religioso shiita extranjero y pasó a formar parte de un pequeño grupo de estudio que lo condujo a viajar para proseguir su formación religiosa y regresar años después para desplegar una intensa actividad. Su tránsito, de la vertiente a la que pertenecía su familia hacia el sufismo y luego hacia el shiismo fue realizado a partir de la desafiliación crítica de las adhesiones anteriores. Entre quienes habían realizado éstos y otros tránsitos, la comparación aparece como un elemento fundamental para el trazado de fronteras entre las diferentes opciones de una misma tradición

\footnotetext{
${ }^{18}$ Limito esta categoría a los casos en los que existe desafiliación doctrinal, y a veces institucional, de la adhesión anterior y la actual es tenida por los sujetos como exclusiva.
} 
religiosa. Doctrinas y prácticas son puestas a la luz de las etapas por las que los sujetos fueron transitando y son cuestionadas en forma total o parcial, junto a formas de liderazgo y modelos de comunidad. En todos los casos, los tránsitos supusieron desafiliaciones institucionales pero una continuidad y permanencia en la religión. La valoración del tránsito intra-islámico realizado fue exaltada muchas veces como vinculada a tomar al Islam como una opción y no como un legado cultural y las desafiliaciones como búsquedas de pureza y corrección traducidas en una intensificación de la adhesión religiosa. Ese tránsito parecía experimentarse, como expresara uno de nuestros entrevistado, s como un "hacerse más musulmán”.

\section{e) En la búsqueda de la práctica}

En distintas instancias de trabajo de campo nos deparamos con algunos casos en que los individuos permanecían en una búsqueda prolongada de retornar o reasumir una creencia que consideran como un destino de origen. Si bien frecuentaban espacios de sociabilidad árabe islámicos no practicaban la religión en lo que concierne a sus rituales y expresaban estar en una posición ambigua respecto a definirse como creyentes. Podemos tomar la trayectoria de Hassan como ejemplo de uno de esos casos, él es un comerciante exitoso que desde joven participó activamente en instituciones del asociacionismo árabe, promueve actividades de difusión cultural y de militancia por la causa palestina, destinando recursos para solventar eventos, charlas, programas de radio, etc. Hijo de inmigrantes libaneses recuerda que su padre era un musulmán observante que le daba suma importancia a la religión y le exigía no sólo seguir la práctica sino también instruirse en asuntos religiosos, exigencia que Hassan desde niño no logró satisfacer. Con el paso del tiempo la tensión entre esas expectativas y sus elecciones personales se fue agudizando, al punto de tener que buscar un trabajo a temprana edad y vivir en permanente enemistad familiar. Hasta el presente 
Hassan afirma que nunca cuestionó su identidad cultural árabe (libanesa) pero sí su práctica religiosa. En realidad expresa haber experimentado siempre esta situación como algo problemático, desearía ser religioso y practicar el Islam pero por algún motivo que siempre intenta descubrir no logra hacerlo. Habiéndose informado en general sobre los contenidos de distintas religiones no tiene dudas sobre la superioridad del Islam. Se interesa particularmente por la demostración de que el Corán contiene la base de la ciencia moderna y sus descubrimientos y considera que una sociedad regida por las normas del Islam resolvería muchos de los problemas actuales. Manteniéndose siempre dentro de los círculos de sociabilidad árabe islámicos, comenzó hace varios años a vincularse con referentes religiosos del shiismo, vertiente que dice seguir de un modo ideológico pero no religioso y cuya difusión facilita por distintos medios a su alcance. Algunos de sus amigos también manifestaron no ser practicantes pero adherir en general a los principios y modos de vida de la religión. Uno de ellos nos relataba su caso intentado explicar que, a diferencia de Hassan, esto se debía a no haber recibido una educación religiosa por parte de sus padres y tampoco habérsela podido transmitir a sus hijos y nietos. Según decía, su padre sólo le había dicho que nunca coma cerdo, el por qué y otros pocos conocimientos los había ido adquiriendo ya adulto y en una forma que consideraba incompleta. Hace casi dos décadas, en ocasión de la visita a su ciudad de un líder religioso shiita, Hassan recuerda que rezó por primera vez en su vida y que sintió una sensación de paz que se prolongó por varios meses. Sin embargo, no volvió a repetir la experiencia, si bien no se define como ateo ni como agnóstico, se considera en medio de una búsqueda incesante de "sentir" la religión a la cual supone pertenecer por origen y destino pero cuya adhesión no logra consumar. 


\section{Conclusiones}

El espacio de la adhesión al Islam incluye tanto a los convertidos como a los musulmanes de origen. Ambos espacios son dinámicos, púes ninguna institución parece ya tener una membresía natural que reproduzca la comunidad por mera tradición. Prestar atención a las narrativas de los conversos nos permitió ver el predominio de ciertos lenguajes para expresar el camino que los condujo a adoptar la nueva religión. Aunque reconocemos que cada institución establece normas y fronteras para definir la forma de incluir a los nuevos adeptos y que éstos también transforman esas normas y fronteras, en este texto nos interesamos por la padronización que asumen los discursos de la conversión, más allá de las inserciones institucionales que, sin dudas, también los moldean. Los incipientes estudios sudamericanos sobre la conversión al Islam podrían beneficiarse atenuando el sesgo localista para establecer comparaciones y dialogar con una literatura sobre otros contextos que, en el presente, es ya abundante. Las formas de adhesión de los musulmanes de origen parece ser un espacio tan complejo e individualizado como el de los conversos. Si bien el hecho de "nacer" dentro de la religión acciona una serie de reconocimientos de pertenencia en los espacios de socialización comunitarios, a lo largo del curso de vida la adhesión es dinámica y se torna objeto de reflexión retrospectiva. Mientras algunos expresan su continuidad valorizando la preservación de una tradición de origen, un legado a conservar y transmitir, otros cuestionan ese "mecanismo" o insisten en adicionarle la elección y la convicción, también vimos que la reasunción puede ser experimentada como conversión y como un despertar o que la adhesión puede experimentarse como de una intensidad creciente a medida que se transita por dimensiones doctrinales o institucionales más satisfactorias o, incluso, que algunos permanecen en los espacios comunitarios buscando tornarse practicantes. Probablemente, los lenguajes de conversión predominantes aquí detectados y las tipificaciones sobre los modos de adhesión de los musulmanes de origen no agoten las variedades de 
experiencias, pero indican la dinámica de un campo que se presenta cada vez más diversificado y en expansión.

\section{REFERENCIAS}

AHMED, Akbar. Muslim converts: shame and honor in a time of excess. In: Journey into America: the challenge of Islam. Washington: Brookings Institution Press, 2010. p. 303-353.

AKMIR, Abdeluahed. La inmigración árabe en Argentina: 1880-1980. 1990.f.450. Tesis (Doctorado)-Universidad Complutense de Madrid, Facultad de Geografía e Historia, Madrid.

DAYNES, Sara. Processus de conversion et modes d'identification à l'islam: l'exemple de la France et des Etats-Unis. Social Compass, Thousand Oaks, v. 46, n. 3, p. 313-323, 1999.

DRESSLER, Markus; KLINKHAMMER, Gritt (Ed). Sufis in western society: global networking and locality. New York: Routledge, 2009.

FERREIRA, Francirosy. Observando o Islã em São Paulo: nascidos e revertidos ao Islã. In: MONTENEGRO, Silvia; BENLABBAH, Fatiha (Org.). Muçulmanos no Brasil: comunidades, instituições, identidades. Rosario: UNR Editora/IEHL, 2013. p.115-141.

FRIGERIO, Alejandro. Pasajes y conversiones: una mirada sobre el tránsito religioso entre Argentina y Brasil. In: RENOLD, Juan Mauricio. Miradas antropológicas sobre la vida religiosa III. Buenos Aires: CICCUS, 2012. p. 145-170.

KERMAN, Analía. Construcción de la subjetividad ascética: estudio etnográfico de un grupo sufí-islámico en Buenos Aires. 2007.186f. Tesina (Graduación)-Universidad de Buenos Aires, Facultad de Filosofia y Letras, Buenos Aires.

KÖSE, Ali. The journey from the secular to the sacred: experiences of native British converts to Islam. Social Compass, Thousand Oaks, v.46, n. 3, p. 301-12, 1999.

KÖSE, Ali. Conversion to Islam: a study of native British converts. New York: Kegan Paul International, 1996.

MANSSON MCGINTY, Anna (Ed). Becoming Muslim: western women's conversions to Islam. New York: Palgrave Macmillan, 2006.

MONTENEGRO, Silvia. Dilemas identitários do Islã no Brasil: a comunidade muçulmana do Rio de Janeiro. 2000. 334 f. Tese (Doutorado) - Universidade Federal do Rio de Janeiro, Programa de Pós-Graduação em Antropologia e Sociologia, Rio de Janeiro. 
MONTENEGRO, Silvia; BENLABBAH, Fatiha (Org.). Muçulmanos no Brasil: comunidades, instituições, identidades. Rosario: UNR Editora/IEHL, 2013.

MONTENEGRO, Silvia. El Islam en la Argentina contemporánea: estrategias institucionales y modos de estar en el espacio nacional. Estudios Sociológicos, Ciudad del Mexico, v. 32, n. 96, p. 593-617, 2014.

MONTENEGRO, Silvia. Contextos locales y expresiones contemporáneas del Islam. In: MALLIMACI, Fortunato. Modernidad, Religión y Memoria. Buenos Aires: Ediciones Colihue, 2007, p. 93-101.

PINTO, Paulo Gabriel Hilu da Rocha. Novos espaços do islã: comunidades muçulmanas na Europa e no Brasil. In: PINTO, Paulo Gabriel Hilu da Rocha. Islã: religião e civilização - uma abordagem antropológica. São Paulo: Editora Santuário, 2010. p.195-219.

RAMBO, Lewis; FARHADIAN, Charles. Introduction. In: RAMBO, Lewis. The oxford handbook of religious conversion. New York: Oxford University Press, 2014. p.1-25.

RAMOS, Vlademir. Conversão ao Islão: uma análise sociológica da assimilação do ethos religioso na sociedade muçulmana sunita em São Bernardo do Campo na região do grande ABC. 2003. 403 f. Dissertação (Mestrado) - Universidade Metodista de São Paulo, Programa de Pós-Graduação em Ciências da Religião, São Paulo.

RAMOS, Vlademir. Conversão ao Islã: estudo sobre a conversão em São Bernardo do Campo. In: MONTENEGRO, Silvia; BENLABBAH, Fatiha (Org.). Muçulmanos no Brasil: comunidades, instituições, identidades. Rosario: UNR Editora/IEHL, 2013. p.5590.

SOMMERS, Margaret. The narrative constitution of identity: a relational and network approach. Theory and Society, Amsterdan, v. 5, n. 23, p. 605-649, 1994.

SULTÁN, Madelaine. Choosing Islam: a study of Swedish converts. Social Compass, Thousand Oaks, v. 46, n. 3, p. 325-335, 1999.

VAN NIEUWKERK, Karin. Women embracing Islam: gender and conversion in the west. Austin: University of Texas Press, 2006.

WESTERLUND, David (Ed). Sufism in Europe and North America. New York: Routledge-Curzon, 2004.

WOHLRAB-SAHAR, Monika. Conversion to Islam: between syncretism and symbolic battle. Social Compass, Thousand Oaks, v. 46, n. 3, p. 351-362, 1999.

ZUBRZYCKI, Bernarda; AGNELLI, Silvina. "Allá en África, en cada barrio por lo menos hay un senegalés que sale de viaje”. La migración senegalesa en Buenos Aires.

Cuadernos de Antropología Social, Buenos Aires, n. 29, p. 135-152, 2009. 